\title{
HYPERTENSIVE RETINOPATHY - PREVALENCE, RISK FACTORS AND COMORBIDS
}

\author{
Velure Raja Rao Mohan Rao', Ravishankar Natarajaboopathy², Krishna Moorthy Sangeeth Kumar3, Velure Mohan Rao Jyostnaa Grace
}

1 Professor and HOD, Department of General Medicine, Chengalpattu Medical College.

${ }^{2}$ Assistant Professor, Department of General Medicine, Chengalpattu Medical College.

3Junior Resident, Department of General Medicine, Chengalpattu Medical College.

4 Undergraduate, Department of General Medicine, Chengalpattu Medical College.

ABSTRACT

\section{BACKGROUND}

Hypertension is one of the most important current health problems with complications like coronary heart disease, stroke, chronic kidney disease and retinopathy. Hypertensive retinopathy is regarded as one of the independent indicator for systemic morbidity and mortality. This study aims at studying the prevalence of hypertensive retinopathy, the risk factors, associated factors and comorbid conditions of it.

\section{MATERIALS AND METHODS}

A cross-sectional study in 120 hypertensive patients in Chengalpattu Medical College is conducted for the prevalence of HT retinopathy and the influence of age, sex, systolic BP, duration of HT, body mass index and lipids on retinopathy were also studied. The prevalence of comorbid conditions like coronary heart disease, stroke, chronic kidney and chronic obstructive lung disease were also studied.

\section{RESULTS}

The prevalence of HT retinopathy among HT patients is 41.5\%. Age, female sex, systolic BP, duration of HT are significant risk factors of HT retinopathy. A high serum levels of total cholesterol, LDL cholesterol and triglyceride are associated with HT retinopathy. Coronary artery disease and stroke are significantly associated comorbidities of HT retinopathy.

\section{CONCLUSION}

There is an increased prevalence of retinopathy among hypertensive patients; the risk factors both modifiable and non-modifiable increases the prevalence of retinopathy. The comorbid illnesses also increase the occurrence of retinopathy.

\section{KEYWORDS}

Hypertension, Retinopathy, Risk Factors, Comorbid Illness.

HOW TO CITE THIS ARTICLE: Rao VRRM, Natarajaboopathy R, Kumar KMS, et al. Hypertensive retinopathy - prevalence, risk factors and comorbids. J. Evolution Med. Dent. Sci. 2016;5(93):6872-6874, DOI: 10.14260/jemds/2016/1553

\section{BACKGROUND}

Hypertension is one of the leading cause of global burden of the disease. Approximately, 7.6 million deaths and 92 million disability adjusted life years world-wide were attributable to high blood pressure since 2001. World Health Organisation defines Hypertension as a rise in blood pressure of systolic above 140 and diastolic above $90 \mathrm{mmHg}$ that increases the risk for cerebral, retina, cardiac and renal events and therefore an increase in complications like coronary heart disease, stroke, chronic kidney disease and retinopathy.

\section{MATERIALS AND METHODS}

This study was conducted in 120 hypertensive patients who attended the Hypertension Clinic of Chengalpattu Medical College Hospital of age above 40 years during October 2015 to September 2016. Patients with secondary hypertension,

Financial or Other, Competing Interest: None.

Submission 18-10-2016, Peer Review 11-11-2016,

Acceptance 17-11-2016, Published 21-11-2016.

Corresponding Author:

Dr. Velure Raja Rao Mohan Rao,

Professor and HOD,

Department of General Medicine,

Chengalpattu Medical College.

E-mail: doctormarchman@rediffmail.com

DOI: $10.14260 /$ jemds/2016/1553 critically ill patients were excluded. After getting the informed consent, patients underwent retinal examination by a trained ophthalmologist and were classified into 4 grades according to Keith-Wagener-Barker scale.

Grade 1 - When there was mild generalised retinal arteriolar narrowing.

Grade 2 - More severe generalised narrowing, focal areas of arteriolar narrowing and arteriovenous nicking.

Grade 3 - Consisted of Grades 1 and 2 signs plus the presence of retinal haemorrhage, microaneurysms, hard exudates and cotton-wool spots.

Grade 4 - Also referred to as accelerated (Malignant) hypertensive retinopathy with signs of the preceding three grades plus optic disk swelling and macular oedema.

The parameters such as age, gender, duration of hypertension, comorbid illnesses, details of anti-HT drugs are obtained from detailed history. The height of the participants was measured in meters by asking them to stand barefoot by facing the back adjacent to the wall and by keeping a scale straight on the head. For measuring the weight, the patients were asked to stand on the weighing machine without slippers and with minimal clothing and the readings were noted in kilograms. The body mass index was calculated from the height and weight of the patients using the formula.

Body Mass Index = Weight (Kg)/Height ${ }^{2}$ (Meters).

Blood pressure was measured in the right arm of the patient in sitting position after the patient had rested for 30 
mins. The arm should be at the level of the heart while measuring BP. Patients were also asked to abstain from smoking and caffeine ingestion for duration of 6 hours previous to measuring BP. Around $5 \mathrm{~mL}$ of venous blood was collected after overnight fasting for 8 hours' duration. Serum total cholesterol, triglyceride and high density lipoprotein cholesterol (HDL - cholesterol) were determined by enzymatic methods. Low density lipoprotein - cholesterol (LDL cholesterol) and very low density lipoprotein - cholesterol (VLDL - C) was calculated using the formula of Friedewald.

LDL-c $=$ TC $-($ HDL + VLDL $)$.

When serum triglyceride concentration was greater than $400 \mathrm{mg} / \mathrm{dL}$, LDL - cholesterol was determined directly by enzymatic method using commercial kits.

All the statistical analyses were done using the Statistical Package for Social Sciences Software Version 17.

\section{RESULTS}

\begin{tabular}{|c|c|}
\hline Profile & Values \\
\hline Age (Years) & $59.51 \pm 13.93$ \\
\hline $\begin{array}{c}\text { Systolic Blood } \\
\text { Pressure (mmHg) }\end{array}$ & $155.3 \pm 12.6$ \\
\hline Duration of HT (Years) & $5.25 \pm 2.06$ \\
\hline Body Mass Index (kg/m²) & $27 \pm 5.3$ \\
\hline Total Cholesterol (mg/dL) & $180.9 \pm 28.3$ \\
\hline LDL Cholesterol (mg/dL) & $115.8 \pm 21.5$ \\
\hline HDL Cholesterol (mg/dL) & $34 \pm 9.3$ \\
\hline Triglycerides (mg/dL) & $155 \pm 37$ \\
\hline \multicolumn{2}{|c|}{ Table 1. Demographic, Anthropometric } \\
and Clinical Profile of Patients \\
\hline
\end{tabular}

\begin{tabular}{|c|c|}
\hline Grades & Percentage \\
\hline $1(\mathrm{n}=22 / 120)$ & $18.33 \%$ \\
\hline $2(\mathrm{n}=12 / 120)$ & $10 \%$ \\
\hline $3(\mathrm{n}=24 / 120)$ & $11.6 \%$ \\
\hline $4(\mathrm{n}=2 / 120)$ & $1.66 \%$ \\
\hline Total $(\mathrm{n}=50 / 120)$ & $41.5 \%$ \\
\hline \multicolumn{2}{|c|}{ Table 2. Prevalence of Retinopathy } \\
\hline
\end{tabular}

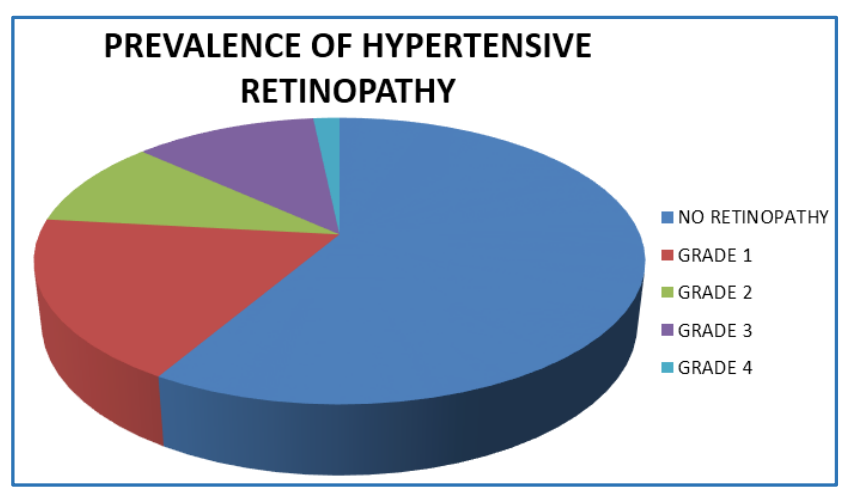

\begin{tabular}{|c|c|c|c|c|}
\hline $\begin{array}{c}\text { Sl. } \\
\text { No. }\end{array}$ & $\begin{array}{c}\text { Risk } \\
\text { Factors }\end{array}$ & With HR & Without HR & P Value \\
\hline 1 & $\begin{array}{c}\text { Age } \\
\text { (Years })\end{array}$ & $66.4 \pm 13.2$ & $54.6 \pm 12.33$ & $<0.0001$ \\
\hline 2 & $\begin{array}{c}\text { Sex } \\
(\mathrm{M}: \mathrm{F})\end{array}$ & $22: 28$ & $46: 24$ & $=0.0248$ \\
\hline 3 & $\begin{array}{c}\text { SBP } \\
(\mathrm{mmHg})\end{array}$ & $164.24 \pm 12.54$ & $148.97 \pm 7.96$ & $<0.0001$ \\
\hline
\end{tabular}

\begin{tabular}{|c|c|c|c|c|}
\hline 4 & $\begin{array}{c}\text { Duration } \\
\text { of } \\
\text { HT } \\
(\text { Years })\end{array}$ & $6.60 \pm 1.57$ & $4.26 \pm 1.77$ & $<0.0001$ \\
\hline 5 & $\begin{array}{c}\mathrm{BMI} \\
\left(\mathrm{kg} / \mathrm{m}^{2}\right)\end{array}$ & $27.31 \pm 5.49$ & $26.79 \pm 5.17$ & $=0.5927$ \\
\hline \multicolumn{4}{|c|}{ Table 3. Risk Factors of Hypertensive Retinopathy } \\
\hline
\end{tabular}

\begin{tabular}{|c|c|c|c|l|}
\hline $\begin{array}{c}\text { Sl. } \\
\text { No. }\end{array}$ & Lipids & With HR & Without HR & P Value \\
\hline 1 & $\begin{array}{c}\text { Total } \\
\text { Cholesterol } \\
\text { (mg/dL) }\end{array}$ & $201 \pm 27.87$ & $116.25 \pm 17.76$ & $<0.0001$ \\
\hline 2 & $\begin{array}{c}\text { LDL } \\
\text { Cholesterol } \\
\text { (mg/dL) }\end{array}$ & $130.16 \pm 21.6$ & $105.6 \pm 14.6$ & $<0.0001$ \\
\hline 3 & $\begin{array}{c}\text { HDL } \\
\text { Cholesterol } \\
\text { (mg/dL) }\end{array}$ & $33.92 \pm 10.11$ & $34.06 \pm 8.83$ & $=0.9373$ \\
\hline 4 & $\begin{array}{c}\text { Triglycerides } \\
\text { (mg/dL) }\end{array}$ & $186.16 \pm 34.38$ & $132.97 \pm 18.11$ & $<0.0001$ \\
\hline \multicolumn{5}{|c|}{ Table 4. Lipid Profiles of Hypertensive Patients } \\
\hline
\end{tabular}

\begin{tabular}{|c|c|c|c|c|}
\hline $\begin{array}{c}\text { Sl. } \\
\text { No. }\end{array}$ & Comorbidities & With HR & Without HR & P Value \\
\hline 1 & $\begin{array}{c}\text { Coronary Heart } \\
\text { Disease }\end{array}$ & $38 / 50$ & $34 / 70$ & 0.0027 \\
\hline 2 & Stroke & $26 / 50$ & $24 / 70$ & 0.0131 \\
\hline 3 & $\begin{array}{c}\text { Chronic Kidney } \\
\text { Disease }\end{array}$ & $18 / 50$ & $32 / 70$ & $=0.2339$ \\
\hline 4 & $\begin{array}{c}\text { Chronic Obstructive } \\
\text { Lung Disease }\end{array}$ & $12 / 50$ & $38 / 70$ & $=0.4163$ \\
\hline \multicolumn{4}{|c|}{ Table 5. Comorbid Illnesses } \\
\hline
\end{tabular}

\section{DISCUSSION}

The prevalence of hypertensive retinopathy among the hypertensive patients in our study is $41.5 \%$ and majority of them are in Grade 1 retinopathy (18.33\%). In a study by S. Erden in Isthanbul, 1 the prevalence of hypertensive retinopathy is $66.3 \%$ among the hypertensive patients and $33.6 \%$ of them are in Grade 1. In Palatini et al 2 study, $51 \%$ of hypertensive patients were affected by retinopathy. Besharati et $\mathrm{al}^{3}$ found retinopathy frequency as $33.9 \%$ in outpatients with newly diagnosed hypertension. In a recent study, ${ }^{4}$ the prevalence of retinopathy was $30.6 \%$ in elderly hypertensive patients.

The patient's age ranges from 38 to 81 years. The mean age of patients with retinopathy is $66.40 \pm 13.2$ years and the age of those with normal fundus is $54.60 \pm 1.33$. The difference is significant $(\mathrm{p}<0.0001)$. In a study carried out by Bastola et al, 5 the mean age of the study group was 58.5 years. In the study by $\mathrm{S}$. Erden, ${ }^{1}$ the mean age is significantly higher among the retinopathy patients when compared with hypertensive patients without retinopathy. In a study conducted for evaluation of hypertension ${ }^{6}$ subjects having retinopathy were mainly concentrated in the 6th decade (69.70\%), increasing thereafter up to $83.78 \%$ who were over 60 years of age. This shows the increasing prevalence of hypertensive retinopathy with increasing age. Yu et al 7 who analysed 3654 older people without diabetes showed that retinopathy is correlated with increased age and existence and severity of hypertension. 
In our study there were 52 females, out of which 28 females had retinopathy. There is a significantly high ( $\mathrm{p}<$ 0.0248 ) female sex preponderance in our study. In the study by $\mathrm{S}$. Erden, ${ }^{1}$ no significant difference was found between women and men in terms of existence or grades of retinal changes.

In our study, patients having retinopathy had mean systolic blood pressure $164+12.54$ and patients having normal fundus had mean systolic blood pressure $148+7.96$, and there is significant association $(\mathrm{p}<0.0001)$ with systolic blood pressure and hypertensive retinopathy. Systolic blood pressure levels were significant risk factors for retinopathy in the study by S. Erden, ${ }^{1}$ but not in the study by G. Palamaner Subash Shantha et al. ${ }^{8}$ This study showed a significant risk due to diastolic BP.

In our study, the duration of hypertension in patients having retinopathy has mean age of 6.6 years and patients having normal fundus has mean age of 4.26 years $(\mathrm{p}<0.0001)$. The duration of hypertension is associated with development of retinopathy also in study by S. Erden. ${ }^{1}$

In our study, patients having retinopathy had mean BMI of 27.31 and patients having normal fundus had BMI of 26.79 and there is no significant association $(\mathrm{P}<0.5927)$ with BMI. In study by G. Palamaner Subash Shantha et al, ${ }^{8}$ the mean BMI was significantly high in hypertensive patients with retinopathy.

In our study, patients having hypertensive retinopathy had significantly ( $p$ value $<0.0001$ ) high serum total cholesterol, LDL cholesterol ( $\mathrm{p}$ value $<0.0001$ ) and triglyceride levels ( $p$ value $<0.0001$ ). The HDL cholesterol levels does not show any significant difference. Similarly, Bastola et $\mathrm{al}^{5}$ in their study also showed that there was a statistically significant difference in the mean serum cholesterol level, mean triglyceride level and mean LDL levels in people with Grade II or higher grades of HR. Badhu et $\mathrm{al}^{9}$ also assessed the serum level of LDL in hypertensive retinopathy. Their results showed a statistically significant $(\mathrm{P}<0.0196)$ higher serum level of LDL-cholesterol in hypertensive patients with retinopathy. Similarly, in the same study the mean serum HDL-cholesterol value for the retinopathy group was 38.68 and that for the no retinopathy group was 39 . There was no significant association between serum HDL-cholesterol and retinopathy. 10 These studies,9-10 also show a significantly high triglyceride levels in the retinopathy patients.

In our study, the patients having Coronary artery disease and Stroke shows significant association with hypertensive retinopathy and chronic kidney disease and Obstructive lung disease does not show any significant association. These results are similar to that of the study by Kabedi et al. ${ }^{11}$ In a study conducted by Tien Y Wong et al ${ }^{10}$ after controlling for systolic blood pressure, diabetes, glycosylated haemoglobin levels and other risk factors, retinopathy was associated with increased cardiovascular mortality.

\section{CONCLUSION}

The prevalence of HT retinopathy among HT patients is $41.5 \%$. Age, female sex, systolic BP, duration of HT are significant risk factors of HT retinopathy, but the Body Mass Index is not a risk factor. A high serum levels of Total cholesterol, LDL cholesterol and triglyceride are associated with HT retinopathy, but high HDL cholesterol levels are not. Coronary artery disease and stroke are significantly associated comorbidities of HT retinopathy, whereas chronic kidney disease and chronic obstructive lung disease are not significantly associated with HT retinopathy.

\section{REFERENCES}

1. Erden S, Bicak E. Hypertensive retinopathy: incidence, risk factors, and comorbidities. Clinical and Experimental Hypertension 2012;34(6):397-401.

2. Palatini P, Penzo M, Bongiovi S, et al. Role of ophthalmoscopy in arterial hypertension: a problem revisited. Cardiologia 1991;36(9):713-22.

3. Besharati MR, Rastegar A, Shoja MR, et al. Prevalence of retinopathy in hypertensive patients. Saudi Med J 2006;27(11):1725-8.

4. Shantha GP, Srinivasan Y, Kumar AA, et al. Can retinal changes predict coronary artery disease in elderly hypertensive patients presenting with angina? Am J Emerg Med 2010;28(5):617-21.

5. Bastola P, Pun CB, Koirala S, et al. Fasting serum lipids and fundus changes in hypertensive patients. Nepal J Med Sci 2012;1(2):103-7.

6. Gupta RP, Gupta S, Gahlot A, et al. Evaluation of hypertensive retinopathy in patients of essential hypertension with high serum lipids. Medical Journal of Dr. D.Y. Patil University 2013;6(2):165-9.

7. $\mathrm{Yu}$ T, Mitchell P, Berry G, et al. Retinopathy in older persons without diabetes and its relationship to hypertension. Arch Ophthalmol 1998;116(1):83-9.

8. Shantha GP, Kumar AA, Bhaskar E, et al. Hypertensive retinal changes, a screening tool to predict microalbuminuria in hypertensive patients: a crosssectional study. Nephrol Dial Transplant 2010;25(6):1839-45.

9. Badhu B, Dulal S, Baral N, et al. Serum level of low-density lipoprotein cholesterol in hypertensive retinopathy. Southeast Asian J Trop Med Public Health 2003;34(1):199-201.

10. Wong TY, Klein R, Nieto FJ, et al. Retinal microvascular abnormalities and 10-year cardiovascular mortality: a population-based case-control study. Ophthalmology 2003;110(5):933-40.

11. Kabedi NN, Mwanza JC, Lepira FB, et al. Hypertensive retinopathy and its association with cardiovascular, renal and cerebrovascular morbidity in Congolese patients. Cardiovascular Journal Africa 2014;25(5):228-32. 